\title{
A payload-ignition theory of adult-oriented humour: TUUTU (a Thought that is Unmentionable and Unmentioned, Triggered Unexpectedly)
}

\author{
Rajeev D. S. Raizada \\ Version 0.1 \\ June 19, 2020
}

\begin{abstract}
A funny joke achieves a sort of sleight-of-hand: in its set up, it sneaks a payload of ordinary-seeming but actually combustible ingredients into your mind. The punchline then induces a mindshift, which jostles those ingredients around. This mindshift leads to the "Aha" moment of you getting the joke: the payload ignites, producing an unmentionable thought that pops up unexpectedly into your head. That sudden appearance in your mind of an unmentionable thought is, the present theory claims, the crucial ingredient that makes adult-directed humour funny. That claim and the payload-ignition model together form the two novel ingredients of the theory of humour that is proposed here. "Unmentionable" here means something that one would not say out loud in polite company, due to it being outrageous in some way, e.g. taboo, rude, or titillating. This unmentionablethought payload is proposed to be a crucial and previously overlooked characteristic of adult-oriented humour. However, it is noticeably absent from child-friendly humour and from most puns, thereby explaining why such jokes are rarely very funny, and why studying puns may have obscured the role of unmentionable thoughts from previous theories. Existing theories of humour have individually devoted their attention only to one aspect of the payload-ignition combination: the classical theories of release and of superiority focused only on the payload, and contemporary theories such as incongruity resolution, bisociation, semantic scripts and error detection have focused only on the mindshift that triggers ignition. The present proposal is consistent with those previous theories, but extends them by adding the new elements of the unmentionable thought and the payload-ignition framework. Examples are presented and analysed of jokes and the unmentionable thoughts that they elicit. It is also shown how removing the unmentionable thought from a joke, while leaving all other elements the same, drains the joke of its humour. The present theory does not claim single-handedly to capture all aspects of humour, and some examples are discussed that remain beyond its grasp. However, it does newly highlight two crucial aspects, missed by previous theories, of what makes a joke funny. Finally, several testable predictions generated by the theory are presented.
\end{abstract}

\section{Introduction: an unmentionable thought that pops up in your mind}

Consider the sort of joke that one would not tell to children. Here is an example, which stuck in my mind perhaps because it came from a source towards whom I was not positively predisposed, 
and who had a straight-laced persona: Laura Bush, the then First Lady, was telling a story about her husband George W. at the White House Correspondents' Dinner (Bumiller. 2005):

"He's learned a lot about ranching, since that first year, when he tried to milk a horse. What's worse, it was a male horse."

This first part of the joke, about trying to milk a horse, induces one slightly unmentionable thought in the mind of the listener (namely, "My husband is the President, and a lot of people think he's a bit stupid, and guess what, I sort of agree"). But then the next line, about how the horse was male, triggers a much more unmentionable thought in the listeners' heads. I will refrain here from explicitly spelling out exactly what that thought is.

What makes the joke funny, I wish to argue, is the experience of finding this unmentionable thought suddenly and unexpectedly popping up in your head. If there is an audience, its members, while laughing after such a joke, often turn to each other with a look that wordlessly says "Oh, wow, you and I are both having that outrageous thought at the same time."

The present theory proposes a payload and ignition model of how such jokes work. The payload consists of the concepts that will subsequently recombine and ignite in a surprising and unmentionable burst. In this case, they are the ideas, individually unremarkable, of milking and of horses. After those ideas have been snuck into your head, a trigger causes them to be reinterpreted. This is rather like taking a combustible mixture and shaking it around: the result is ignition. That ignition releases an unexpected and unmentionable thought into your mind, and that is the experience that is funny.

A crucial aspect of this process is that, when it enters the mind, the unmentionable thought payload must not yet be ignited. That is, the thought must be not only unmentionable, but also unmentioned.

What sorts of triggers cause ignition? This question, I believe, has been the exclusive focus of many theories of humour. It is certainly an important question, but it distracts attention from the equally important question of what the ignition event releases in the mind, namely an unmentionable thought. Perhaps the most important sort of trigger is incongruity, as is emphasised by some prominent theories of humour (Shultz, 1972; Suls, 1972). In this case, the incongruity arises when, to the set of concepts 'milking' and 'horse', the additional concept 'male' gets added. This gets recognised as a violation (McGraw and Warren, 2010) or an error of interpretation (Hurley et al., 2011), and leads to a reversal (Apter, 1982), or switch of semantic script (Raskin, 1985; Attardo and Raskin, 1991). "Hmm, wait a minute. Male horses don't produce milk. So, if he's trying to milk a male horse, then... Oh, haha!"

What such theories appear to have overlooked is that equally incongruous but different versions of the joke could also lead to sudden reinterpretations and switches of semantic script, but would fail to be funny on grounds of not inducing an unmentionable thought. Consider the following alternative punchline: "What's worse, it was a dead horse." The idea of trying to milk a dead horse is very incongruous indeed, and it also leads to a sudden change in how the horse-milking scenario gets interpreted. However, it no longer elicits in your mind any unmentionable thoughts about how exactly the horse might be producing any milk-like fluid. Although it is incongruous, absurd, a violation, and causes a sudden reinterpretation, the alternative punchline about a dead horse may be puzzling and disorienting, but it is simply not very funny. (Note: my mere assertion that the male-horse actual version of the joke is funnier than the dead-horse alternative should carry very little weight. My hope is that the reader will agree on which version is funnier, but even then the sample size would still only be two. Clearly, such claims can and should be tested empirically. A variety of testable predictions generated by this theory are presented at the end of this paper.) 
New theories often arise from novel reconfigurations of existing ingredients, and the present one is no exception. The association between unmentionable topics and humour goes back at least to Freud (1905), the importance of the unexpected is emphasised by Incongruity Theory (Shultz, 1972: Suls, 1972). A crucial aspect of this unmentionable payload is that it is not actually included in the overt content of the joke, but instead must be absent and only hinted at. This absence gives space for the unmentionable thought to be internally generated in the listener's head, at the moment when they get the joke. The fact that humor leaves much unmentioned or implicit has been pointed out in the context of linguistic pragmatics (Attardo, 2017: Dolitsky, 1983). However, the novel claim here goes beyond the observation that these phenomena are associated with humour. Instead, the claim is that the unexpected appearance in your mind of an unmentionable and unmentioned thought is the very thing that makes a joke funny.

\section{Puns lead down the garden path}

Most puns, and most kid-friendly jokes, lack any unmentionable element. Here's an example:

"Why does a seagull fly over the sea? Because if it flew over the bay, it would be a baygull."

Rather than triggering any unmentionable thought, the hidden premise of puns usually boils down to nothing more than "Hey, look, this word sounds just like that other word!" Such a pun might be clever and mildly entertaining, but it will not typically be very funny (see the section on testable predictions, at the end of this paper).

Similarly, it is the very absence of any unmentionable element that makes kid-friendly jokes suitable for children, so they too often rely on punning. Jokes about flatulence are a possible exception: they are only very mildly unmentionable, and are very common in movies aimed at kids. This appears to be the limit on how transgressive kid-friendly humour is allowed to get.

Some subdomains of humour research, such as computational studies (e.g., Binsted and Ritchie, 1997; Kao et al. 2016; Ritchie, 2004; Miller et al. 2017) have devoted a lot of attention to puns. Although puns have the advantage of being amenable to analysis by computational semantic models, they have, according to the present theory, the severe disadvantage of lacking the core ingredient of what makes jokes genuinely funny, namely the unexpected triggering of an unmentionable thought. Puns are indeed more often groan-worthy than funny.

Another difficult challenge for computational theories of humour, perhaps not insurmountable but certainly not yet addressed, is the fact that the unmentionable thought must also be unmentioned. The joke quashes its own attempted humour if it spells out that thought directly. Instead, it must only be hinted at. Pragmatic inference of implicit but unstated information is a very challenging problem for natural language processing systems. Progress in almost all areas of NLP has been rapidly accelerating in recent years, but this problem, which the present theory suggests will be central to any analysis of genuine humour, still seems to be quite far beyond our current grasp.

In order really to be funny, a pun needs also to induce an unmentionable thought, e.g. this one from Dorothy Parker, who, on hearing that an actress friend had broken her leg while working in London, remarked: "She must have done it sliding down a barrister" (Woollcott, 1934).

A similar example is the following, provided by Hurley et al. (2011, p.134): "The butcher backed up into the meat grinder, and got a little behind in his work." Here, I wish to argue, the main source of 
the humour is not merely the sudden reinterpretation of the word 'behind,' but is also the feeling of an unmentionable thought popping up unexpectedly in your head, namely about the type of meat that some of his customers are unknowingly going to be eating. The hypothesis that puns will be rated as funnier if they trigger an unmentionable thought is included in the list of testable predictions at the end of this paper.

\section{Types of humour that are not explainable by this theory}

Puns, then, do not refute the present theory, if one accepts that mere wordplay is usually not very funny. When puns do succeed in being genuinely funny, they do so by additionally incorporating an unmentionable element.

However, there do exist genuinely funny jokes that also lack any unmentionable element. Such jokes often invert our expectations or standard viewpoints in inventive and absurd ways. Examples include much of the humor of Monty Python, and jokes such as the following: "I like an escalator, because an escalator can never break, it can only become stairs." by Mitch Hedberg, and "What is the speed of dark?" by Steven Wright. This theory has little to say about such humour. However, absurdist humour has already been addressed by existing theories, e.g. those of incongruity or cognitive-shifts (e.g., Martin and Ford, 2018; Latta, 2011).

The present theory does not seek to replace existing theories, but instead to extend them by highlighting two important aspects (the payload-ignition model, and the role of unmentionable thoughts) that have previously been overlooked. It does not claim to be a one-size-fits-all explanation of all forms of humour or laughter. For example, it does not seek to explain why playing peek-a-boo with babies, or tickling young children, makes them laugh. Neither does it explain why seeing someone slip on a banana peel can be funny. Those are probably best captured by existing theories, such as Benign Violation (Veatch, 1998: McGraw and Warren, 2010: McGraw et al., 2012). (The argument could perhaps be made that the "falling down, but not badly hurt" banana peel variety of sight-gag triggers the unmentionable thought "Oh, wow, they could have been badly hurt," but this seems like a stretch. Benign violation theory fits this case much more easily). It seems to me unlikely that a single one-liner explanation can account for all forms of humour and laughter, any more than a single factor can explain all the different ways in which food can be tasty.

\section{Ruin a joke by removing the unmentionable thought}

A good test of this theory would be to see whether it is possible to turn a funny joke into an unfunny one by removing its unmentionable thought, while leaving everything else the same. These altered jokes are left as ignition mechanisms without a payload.

Jokes are often tightly constructed, and they rarely lend themselves to being taken apart, edited, and then put back together again. However, occasionally this can be done. As well as testing the present theory, such manipulations also present a challenge to theories of humor that emphasise the structural aspects of a joke.

Consider the following joke, attributed to W. C. Fields:

"Do you believe in clubs for kids?"

"Only when kindness fails." 
Now consider this slightly changed version:

"Do you believe in parties for kids?"

"Only when they show an early interest in politics."

The first version is funny, but the second is barely funny at all (see the section on testable predictions, at the end of this paper). However, their overall structures are very much the same. More specifically, both versions of the joke preserve exactly the same ignition mechanism, which involves a sudden reversal (Apter, 1982) or reinterpretation (Wyer and Collins, 1992) between two opposing but simultaneously possible perspectives: a "bisociation," as described by Koestler (1964). Expressed in terms of the framework of Raskin (1985), there is a change of semantic script from the entertainment script to, respectively, scripts of violent punishment or of politics. Both involve the unexpected discovery of a cognitive error, namely having interpreted an ambiguous word the wrong way (Hurley et al., 2011). Both involve incongruity, which gets resolved when the audience suddenly realises that the initial interpretation of "clubs" or "parties" needs to be revised (Shultz, 1972; Suls, 1972). Both also involve violations of normal expectations about what one would want for children, as in Benign Violation theory (Veatch, 1998; McGraw and Warren, 2010). However, contrary to that theory, the political-party version of the joke is more benign, despite being much less funny.

What, then, is the key difference between the two versions of the joke? This paper wishes to argue that it is the payload: the triggering in the mind of the audience of an unmentionable thought, namely: "Aha, yes, I suppose hitting kids with clubs would help to keep them in line, if kindness fails." You suddenly and unexpectedly find this cruel thought, the public utterance of which would (rightly) make one an instant social outcast, popping into your head. And although this thought was triggered by the joke, it wasn't placed in your head directly. You put it there yourself, or, rather, you found it bubbling up inside your head without any overt external forcing. And that experience, I wish to argue, namely finding a Thought that is Unmentionable and Unmentioned, Triggered Unexpectedly (TUUTU), is the key ingredient of humor that has been missing from previous theories.

In contrast, there is no unmentionable inner thought in the altered version of the joke, which talks about parties and politics. It is a bit odd, and incongruous, to imagine that children would be interested in party politics. But it isn't unmentionable at all. And, for that very reason, it isn't funny either.

Here's another example, a joke from Jerry Seinfeld:

"Men want the same thing from their underwear that they want from women: a little bit of support, and a little bit of freedom."

Now consider the following version, minimally altered by changing just a single word, with the word 'underwear' having been replaced with 'shoes':

"Men want the same thing from their shoes that they want from women: a little bit of support, and a little bit of freedom."

The first version is a lot funnier than the second one (again, a testable prediction). But why? Well, in the second version, you think about a man's foot getting some support, perhaps under the arch, but also having enough room for him to wiggle his toes. In the first version, it's not his toes that you imagine jiggling around, but some different body parts. Describing out loud what you are thinking 
about is not something that you would do in polite company. But suddenly, and unexpectedly, you find that thought in your head, internally generated. And that's what makes it funny.

Here's a final example of making a minimal change to a joke, this one from Mitch Hedberg:

"I used to do drugs. I still do, but I used to too."

Here's a minimally altered version:

"I used to exercise a lot. I still do, but I used to too."

Here again, all aspects of the structure are maintained. In both cases, the audience's expectations are equally violated about what "I used to" typically means: the pragmatic implicature is that the speaker no longer does what he used to do. However, in the first case, the unmentionable and unmentioned thought is unexpectedly triggered: "He sounds like he's talking about having quit drugs, but in fact he still takes drugs, and he's totally fine with that." In the altered version, there is no such unmentionable thought. The speaker is simply using unusual phrasing to describe his continued practice of a healthy activity.

\section{The problem with overlooking that ignition requires a payload}

In the present theory, the humour-producing moment of ignition comes from the joke's raw ingredients being jostled together. What causes this jostling is typically a sudden reinterpretation, and this in turn is often caused by discovering an unnoticed error in the initial interpretation. As was noted above, several theories focus exclusively on this ignition event. According to the present theory, this is indeed a very important ingredient of humour, but the ignition also requires a payload to ignite. That payload, when ignited, releases an unmentionable thought.

Theories that concentrate on the structural aspects of humour sometimes remark in passing that jokes typically take unmentionable topics as their themes. However, their focus on the ignition-triggering aspects of humour tends to result in too little attention being given to the jokes' content. That absence is rarely commented upon explicitly, but the admirably clear and insightful book by Hurley et al. (2011) is an exception. Those authors summarise their theory as follows: "Humor happens when an assumption is epistemically committed to in a mental space and then discovered to have been a mistake." (Hurley et al. 2011, p.121). This error-detection view has the virtue of being broadly general, but that very generality prevents it from specifying what sort of content the detected errors must have if they are to be funny. However, later in the book, the authors specifically remark on the fact that unmentionable topics such as sex and excrement often form the content of humour, but they then go on to suggest that these ingredients are helpful but not required:

"We conjecture that the most effectively transmitted joke-memes have exploited just such a transfer effect by combining the basic mechanism of humor perception with such hotbutton topics as sex, violence, death, excrement, and racial perception, creating emotional priming that heightens one's susceptibility to mirth. The result is a more potent cocktail of types of arousal, enhancing the effect of humor in much the way chocolate or coffee enhances the effect of sugar." (Hurley et al., 2011, p.217) 
According to the present theory, in contrast, these unmentionable ingredients are very much required. That, indeed, is why the theory only applies to adult-oriented humour. Without any unmentionable thought to trigger in the mind of the listener, a joke is not like sugar without coffee, but instead is more like a flame without anything to ignite.

\section{Relation to existing content-based theories of humour}

The minimal alterations illustrated above leave the logical and linguistic structure of a joke intact. Theories that emphasise those aspects of humour, therefore, should have difficulty explaining why the alterations render the jokes much less funny. The difference was not one of structure, but of content: the alteration prevented the triggering of any unmentionable thought.

The altered jokes have been left as ignition mechanisms without a payload. It might be supposed, then, that content-based theories of humour would be well placed to explain such effects. However, I wish to argue that those theories fail in two respects. First, their delineation of humorous content is too vague and general, as compared to the much more specific requirement of an unmentionable thought. Second, by focusing only on content, they end up as content without a ignition mechanism.

In the case of TUUTU theory, the payload is the unmentionable thought, and the ignition mechanism is that it must be unmentioned and unexpected.

\section{The Superiority Theory}

This theory, originating with Plato and developed by Hobbes and others (reviewed in, e.g. Morreall, 2016: Martin and Ford, 2018) does indeed propose content for humour: the feeling that one is better than others. Certainly, many jokes do poke fun at and belittle their targets. However, as described in those reviews and by many others, counter-examples are easy to generate, such as the non-humorous feeling of pity that one can feel for someone in distress.

Many jokes of this sort tend to be unpleasantly sexist or racist, e.g. dumb blonde jokes. Thus, the following joke is presented as an illustrative example, not as an endorsement:

Why did the blonde stare at the carton of orange juice? Because it said 'concentrate'.

Here the unmentionable thought, i.e. the thought that one would not want to state out loud in polite company, would be something along the lines of "You know, women with blonde hair are really stupid."

The present theory suggests which additional ingredients are necessary: the feeling of superiority must be triggered as a thought that is unmentioned, i.e. it must be hinted at by the joke, but cannot form part of its literal wording, and, relatedly, it must be unexpected. As was mentioned above, work in linguistic pragmatics has pointed out that humor leaves much unmentioned or implicit Attardo, 2017; Dolitsky, 1983). However, the Superiority Theory, along with most content-based theories of humour, says nothing about this. One can therefore remove the humour from any superiority-themed joke simply by spelling out its message explicitly. E.g.:

A carton of orange juice had the word 'concentrate' on it. The meaning of this statement was that the juice was made from concentrate. However, a blonde was so stupid that she 
thought it was an instruction telling her to concentrate, rather than a description of the juice. So, she spent a long time staring hard at the carton, trying to concentrate on it.

Thus, this analysis produces a testable hypothesis of how counter-examples to content-based theories of humour can be generated: simply keep the content the same, but remove the element of unexpectedness by spelling out explicitly that which was previously left implicit.

\section{Relief Theory}

This theory, classically expounded by Shaftesbury, Spencer and Freud (reviewed in, e.g. Morreall, 2016. Larkin-Galinanes, 2017; Martin and Ford, 2018), proposes that humor arises from a relief of tension. In Freud's version of the theory, this tension consists of repressed sexual or hostile thoughts. Here again, the present theory is consistent with this, as sexual themes can very often provide the content for unmentionable thoughts. However, again the Relief Theory fails to provide the two key ingredients of the thought being unmentioned and unexpected.

If the release of tension were, on its own, sufficient to produce humour, then pretty much the funniest experiences of all would be having an orgasm, or finally getting to go to the bathroom after a long wait. A person experiencing such release will probably sigh or moan, but will not usually laugh. However, we are getting close to humour here. One rarely describes orgasms or bodily excretions in polite company: they are unmentionable. Thus, they provide the source material for many jokes. What these jokes do with that unmentionable material is that they unexpectedly trigger a thought of it in the listener's mind. That is what happened above in the joke about milking the horse.

\section{Relation to Freud's relief theory}

In his 1905 book "Jokes and their relation to the unconscious," Freud proposed a theory of humour in which jokes enable the release of psychic tension. He divides jokes into those that are 'innocent' and those that are 'tendentious', meaning that they serve a specific aim, typically of the relief of repressed hostility or sexual tension. Speaking of these tendentious jokes, he writes:

"They make possible the satisfaction of an instinct (whether lustful or hostile) in the face of an obstacle that stands in its way. They circumvent this obstacle and in that way draw pleasure from a source which the obstacle had made inaccessible." (Freud, 1905, p.120)

The idea proposed by the present theory, namely that adult-oriented humour becomes funny by triggering an unmentionable thought to pop up in your mind, clearly shares with Freud's view its emphasis on that which is typically repressed. However, the ideas turn out to be opposite in several respects. In the present view, what makes a thought unmentionable is not that you are repressing its expression in your own mind, but instead is that it is not something that you would say out loud to others in polite company. Similarly, the present theory does not require a joke to serve any purpose other than to be funny. For Freud, it must serve to remove an obstacle to an otherwise repressed hostile or sexual goal.

The large difference between Freud's view and the present theory can perhaps best be seen by considering his analysis of telling a smutty joke. He describes it as requiring three people: a man, 
who tells the smutty joke, a woman, who is the object of lust, and a second man, whose presence is interfering with the first man's lustful plans:

Generally speaking, a tendentious joke calls for three people: in addition to the one who makes the joke, there must be a second who is taken as the object of the hostile or sexual aggressiveness, and a third in whom the joke's aim of producing pleasure is fulfilled. ... When the first person finds his libidinal impulse inhibited by the woman, he develops a hostile trend against that second person and calls on the originally interfering third person as his ally. Through the first person's smutty speech the woman is exposed before the third, who, as listener, has now been bribed by the effortless satisfaction of his own libido. (Freud, 1905, p.119)

To modern ears, it sounds rather like the description of a sexual harasser attempting to downplay unwanted advances as "just a joke." Unfortunately, such a scenario is still all too common, but it certainly does not describe the great majority of contemporary humour. When comedians such as Amy Schumer or Sarah Silverman tell sexually-themed jokes on stage, the present theory argues that they create laughs by inducing unmentionable thoughts in the minds of their audience members. Whether that is true or not, whatever it is that they are doing does not remotely fit Freud's model.

\section{Benign Violation Theory}

A much more recent content-related theory of humour is the Benign Violation theory of McGraw and colleagues, building upon work by Veatch (Veatch, 1998; McGraw and Warren, 2010; McGraw et al., 2012). This theory proposes that, in order to be humorous, something must be both a violation of some social norm and also ultimately harmless, i.e. benign.

This theory clearly gets at some important element of truth, because many jokes do seem to meet both of these requirements. However, it is not difficult to construct benign violations that fail to be humorous. For example:

A car approached a traffic intersection, and ran straight through a red light. However, at that moment there did not happen to be any cross-traffic, so nobody was hurt.

Running through a red light is a violation, and the fact that nobody was hurt makes it benign. But that combination does not, in this instance, produce any humour at all.

Here again, the present theory is consistent with the Benign Violation theory, but extends beyond it by suggesting key missing ingredients. The very fact that makes a thought unmentionable is that stating it out loud would be a social violation. However, to be funny for the person silently having the thought, it must not be distressing or aversive. Thus, in that sense it must indeed be benign, at least in that it does not hurt the thinker's own feelings. However, it can be aggressively non-benign to the target of the joke, as is the case for jokes that are racist or sexist.

Thus, although every humorous unmentionable thought is a benign violation, not every benign violation is humorous or involves an unmentionable thought. This is illustrated by the example above of running a red light. There is nothing unmentionable in that description or scenario.

As with the discussion of the Superiority and Relief theories, the present theory also provides the missing ingredients that the unmentionable thought must be unmentioned and unexpected. Benign 
Violation theory does not specify either of these two factors, which are crucial aspects of the ignition mechanism for the unmentionable-thought payload.

\section{Bisociation with or without a payload: a visual illustration}

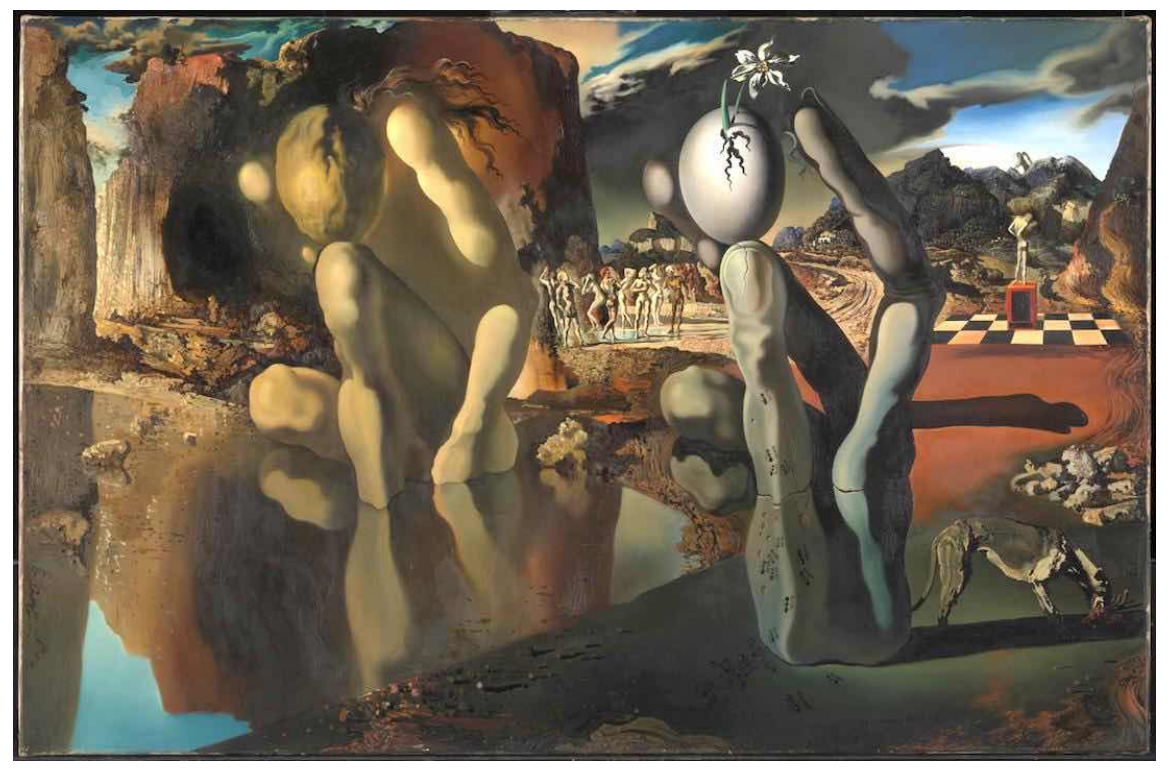

Figure 1: "The Metamorphosis of Narcissus," by Salvador Dali. This painting contains an abundance of the standardly hypothesised elements of humour: bisociation, incongruity, absurdity, and themes of suppressed sexuality. But it is not funny.

Koestler (1964) coined the term "bisociation" to describe the simultaneous interpretation of an item in two opposing ways, and highlighted its importance in humor. In terms of the present theory, bisociation can serve as a very effective ignition mechanism. However, it does not in itself say anything about the presence or absence of the payload of an unmentionable thought.

Bistable visual illusions, such as the Rubin face/vase illusion, seem to be examples of bisociations, as they can be seen in two different ways. However, although it is visual intriguing to experience seeing either a vase in the background or two faces in the foreground, this illusion does not elicit laughter. It might be argued that some additional elements of humour are required, such as incongruity or absurdity.

Surrealist art is full of examples of incongruity and absurdity, such as Magritte's painting "Collective Invention," which depicts a reverse-mermaid with the body of a woman and the head of a fish, or Dali's melting soft watches in "The Persistence of Memory." Several paintings by Dali also exploit visual illusions to produce visual bisociations. An example is the painting "The Metamorphosis of Narcissus," shown in Figure 1. On the left side of this image is the crouching figure of Narcissus gazing at his own reflection in a pool of water, and on the right hand side is the very same set of shapes, now represented as a hand holding an egg with a Narcissus flower sprouting out of it. Scattered around these two central figures are additional incongruous and sexual images, such as a rabid dog and dancing nudes. Thus, this painting contains an abundance of the standardly hypothesised elements of humour: bisociation, incongruity, absurdity, and themes of suppressed sexuality. However, although the overall effect is striking and memorable, it is not funny (this, again, is a hypothesis that can and 


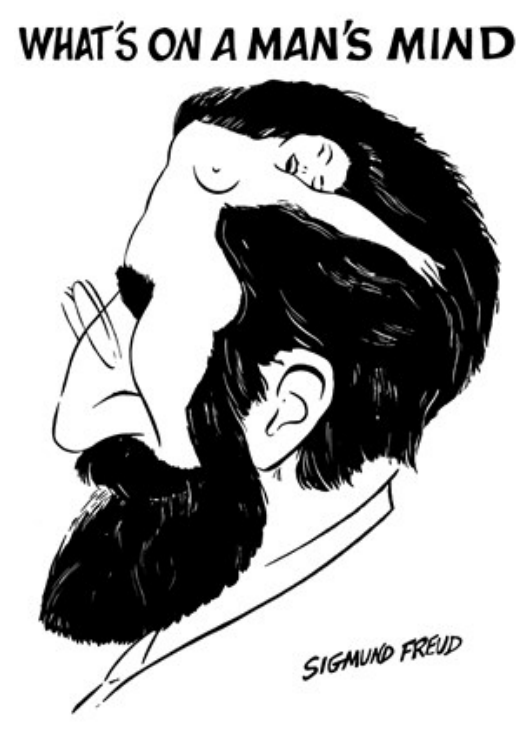

Figure 2: A portrait of Sigmund Freud, with the caption "What's on a man's mind," artist unknown. Like the Dali painting, this picture also involves bisociation. However, unlike that painting, this cartoon also triggers an unmentioned and unmentionable thought. For that reason, it is funny.

should be tested).

According to the present theory, although it has many of the key ingredients of a ignition mechanism, it lacks the payload of triggering an unmentionable thought.

In contrast, compare this with the drawing in Figure 2. This cartoon shares many aspects in common with the Dali painting, especially that of bisociation. Just as the shape of Narcissus crouching in the pond can also be seen as the shape of a hand holding an egg, the facial profile of Freud can be seen as the figure of a naked woman reclining across his forehead. The caption, "What is on a man's mind", thereby also gains two possible meanings: the naked woman is literally on his head (i.e. on his mind), and also triggers the unmentionable and unmentioned thought: "All that men ever think about is sex, according to Freud." The present theory claims that it is the triggering of this unmentionable thought that makes the cartoon funny. Indeed, the image, whose original artist appears to have been lost to time, is widely popular, and can be bought online in the form of a poster, on T-shirts, on mugs, and in many other versions.

Whatever the key difference between Figs. 1 and 2 is that makes the latter funny but the former not, it cannot be bisociation, or the occurrence of a shift in interpretation between different semantic scripts, or the presence of incongruity. Both images share those properties alike.

\section{An unmentionable thought that is purely internally generated: The Count Censored}

The discussion above has provided several examples of neutered jokes, which preserve all the ingredients that are here being referred to as a ignition mechanism, but which fail to be funny due to lacking any unmentionable payload. The converse case, namely an unmentionable thought payload but with barely any ignition mechanism, is much harder to come by. The purest example that I know of is a viral YouTube video called "The Count Censored", available at 


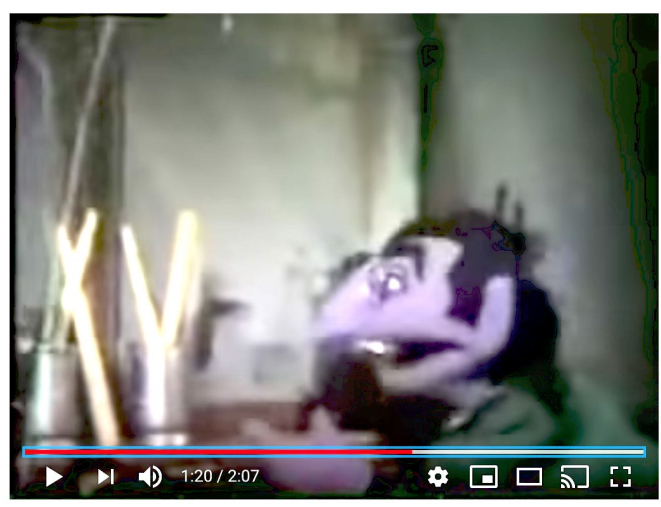

Figure 3: "The Count Censored," a viral YouTube video in which the character Count von Count from Sesame Street sings a song about how he likes to count, in which the word "count" has been bleeped out, every time he says it. It is almost impossible to watch the video without imagining an unmentionable word, purely internally generated, in place of each beep. In that sense, this is somewhat like a humorous version of the phonemic restoration effect (Warren, 1970). The two-minute video is available at https://www.youtube.com/watch?v=6AXPnH0C9UA.

https://www.youtube.com/watch?v=6AXPnH0C9UA.

What is noteworthy about this video is that its humour derives entirely from the occurrence of an internally generated unmentionable thought. In it, the character Count von Count from Sesame Street sings a song about how he likes to count. The only difference between this version and the original is the the word "count" is bleeped out, every time he says it. Such bleeping, of course, is mentally associated with being used to hide a swear word, and this mere association appears to be sufficient to produce ignition. However, the auditory cue of a bleep does not, in itself, provide any information about which word is being bleeped out. Any word that is imagined to fill in the blank must be purely internally generated.

At this point, it is highly recommended that the reader take a moment to watch the two-minute video, as merely reading a description of the effect does not do it justice. What one finds is that it is almost impossible to watch the video without imagining, in the place of each bleep, a word that is very different from, and much more unmentionable than, "count." The overall effect is very funny, almost to a guilt-inducing degree, as one finds oneself astonished by how obstinately some very unmentionable thoughts keep on popping up in one's head while watching a clip from a wholesome and beloved children's TV program.

The very strong sense that one almost literally hears the unmentionable word, when only a beep is present in the actual audio, is very similar to a perceptual phenomenon in speech research known as the Phonemic Restoration Effect (Warren, 1970). In that illusion, the audio of a phoneme from a word gets replaced by the sound of a cough or a noise-burst, but the listener nonetheless still perceives that (actually absent) phoneme as having been heard.

This video provides an excellent illustration of the humorous power of an unmentionable thought, because such thoughts are generated in the viewer purely internally. Literally the only element that operates as a ignition mechanism is as impoverished a stimulus as there could be: the mere sound of a beep. 


\section{Can this theory be used as a method for generating funny jokes?}

It would be nice if this theory could be used as an algorithm for producing humour, but, of course, it cannot. When presented with a joke, the theory may help to recognise and explain why it is funny. Although it can sketch out an abstract-level template for the structure of a joke, it does not tell you how that template should be filled in. That requires creativity, and there does not exist any known formula for that.

Nonetheless, if the present theory is correct, it might perhaps prove useful as a tool for analysing candidate pieces of humour. For example, Hollywood releases many comedies every year, and a disappointingly large proportion of them end up not actually being very funny. At the risk of being speculative, it seems possible that testing candidate screenplays against the criteria of this theory might serve as a useful filtering mechanism, preventing the expense of trying to turn unfunny scripts into actual movie productions.

\section{Summary, and testable predictions}

In conclusion, this paper has argued that a crucial element in humour has been overlooked by previous theories: the experience of suddenly and unexpectedly finding an unmentionable thought popping up in your mind. The acronym TUUTU tries to capture this: a Thought that is Unmentioned and Unmentionable, Triggered Unexpectedly. A novel payload-ignition model was proposed: the overt content of the joke can be thought of as the payload, a combustible mix of concepts which get delivered into your mind in their not-yet-ignited form. The punchline of the joke then jostles those ingredients together, with this typically taking the form of a sudden reinterpretation or shift of perspective. That jostling then triggers an ignition, which releases an unexpected and unmentionable thought in your head. That is the experience, I wish to argue, that makes something funny.

In general, adult-directed humour triggers unmentionable thoughts. In contrast, child-friendly humour, puns and word-play typically lack any unmentionable element. This, according to the present theory, explains why such jokes are usually not very funny.

That last point is one of many assertions that have been made in this paper about what is funny and what is not. I hope that the reader has found such assertions to be plausible, but of course mere plausibility is not enough. Thus, all of these claims could, and should, be tested experimentally, e.g. by collecting ratings from large and representative samples of native English speakers.

Some claims to be tested include the following:

- Adult-oriented jokes, other than the exceptions listed below, will be found to be analysable as triggering an unmentionable thought that is unmentioned and unexpected.

- Exceptions: Purely absurdist humour, puns based only on wordplay, slapstick of the slipping on a banana peel variety.

- The internally generated nature of such unmentionable thoughts can be highlighted by jokeanalogues of the phonemic restoration effect (Warren, 1970), such as the Censored Count video described above. With effort, it should be possible to find, or create, additional humour of this sort.

- The example jokes that are discussed by structure-emphasising theories will be found, upon closer inspection, also to have content that triggers an unmentionable thought. But only if they 
are funny. If they are not funny (as judged by a sample of raters), then they will be found to be of the pure-wordplay variety of puns.

- For adult-oriented jokes that do trigger an unmentionable thought, removing that unmentionable element will greatly reduce the funniness ratings that those jokes receive.

- The cleanest test of the previous hypothesis will be using "minimal alteration" joke pairs, such as the examples given in the above Section titled "Ruin a joke by removing the unmentionable thought."

\section{References}

Apter, M. J. (1982). The experience of motivation: The theory of psychological reversals. Academic Press.

Attardo, S. (2017). Humor and pragmatics. In Attardo, S., editor, The Routledge handbook of language and humor, pages 174-188. Routledge.

Attardo, S. and Raskin, V. (1991). Script theory revis (it) ed: Joke similarity and joke representation model. Humor-International Journal of Humor Research, 4(3-4):293-348.

Binsted, K. and Ritchie, G. (1997). Computational rules for generating punning riddles. Humour: International Journal of Humor Research, 10(1):25-76.

Bumiller, E. (2005). Desperate White House wife, episode 1: The ranch hand. New York Times. https://www.nytimes.com/2005/05/02/politics/desperate-white-housewife-episode-1-the-ranch-hand.html. A video recording of this joke is available at https:/ / www.youtube.com/watch?v=uQ3HIozYPJs.

Dolitsky, M. (1983). Humor and the unsaid. Journal of Pragmatics, 7(1):39-48.

Freud, S. (1905). Jokes and their relation to the unconscious. WW Norton \& Company.

Hurley, M. M., Dennett, D. C., Adams Jr, R. B., and Adams, R. B. (2011). Inside jokes: Using humor to reverse-engineer the mind. MIT press.

Kao, J. T., Levy, R., and Goodman, N. D. (2016). A Computational Model of Linguistic Humor in Puns. Cognitive Science, 40(5):1270-1285.

Koestler, A. (1964). The act of creation. London Hutchinson.

Larkin-Galinanes, C. (2017). An overview of humor theory. In Attardo, S., editor, The routledge handbook of language and humor, pages 4-16. Routledge.

Latta, R. L. (2011). The basic humor process: A cognitive-shift theory and the case against incongruity, volume 5. Walter de Gruyter.

Martin, R. A. and Ford, T. (2018). The psychology of humor: An integrative approach. Academic Press.

McGraw, A. P. and Warren, C. (2010). Benign violations: making immoral behavior funny. Psychol Sci, 21(8):1141-9.

McGraw, A. P., Warren, C., Williams, L. E., and Leonard, B. (2012). Too close for comfort, or too far to care? Finding humor in distant tragedies and close mishaps. Psychol Sci, 23(10):1215-23. 
Miller, T., Hempelmann, C. F., and Gurevych, I. (2017). Semeval-2017 task 7: Detection and interpretation of English puns. In Proceedings of the 11th International Workshop on Semantic Evaluation (SemEval-2017), pages 58-68.

Morreall, J. (2016). Philosophy of humor. In Zalta, E. N., editor, The Stanford Encyclopedia of Philosophy (Winter 2016 Edition). https://plato.stanford.edu/archives/win2016/entries/humor/.

Raskin, V. (1985). Semantic mechanisms of humor. D. Reidel, Dordrecht, Netherlands.

Ritchie, G. (2004). The linguistic analysis of jokes, volume 2. Routledge.

Shultz, T. R. (1972). The role of incongruity and resolution in children's appreciation of cartoon humor. Journal of Experimental Child Psychology, 13(3):456-477.

Suls, J. M. (1972). A two-stage model for the appreciation of jokes and cartoons: An informationprocessing analysis. In Goldstein, J. H. and E., M. P., editors, The psychology of humor: Theoretical perspectives and empirical issues, pages 81-100. Academic Press, New York.

Veatch, T. C. (1998). A theory of humor. Humor: International Journal of Humor Research, 11(2):161-215.

Warren, R. M. (1970). Perceptual restoration of missing speech sounds. Science, 167(3917):392-393.

Woollcott, A. (1934). While Rome Burns. Viking Press.

Wyer, R. S. and Collins, J. E. (1992). A theory of humor elicitation. Psychological Review, 99(4):663. 